\title{
Long-circulating delivery of bioactive polysaccharide from radix ophiopogonis by PEGylation
}

\author{
This article was published in the following Dove Press journal: \\ International Journal of Nanomedicine \\ 10 November 2011 \\ Number of times this article has been viewed
}

\author{
Xiao $\operatorname{Lin}^{1,2}$ \\ Zhuo-Jun Wang ${ }^{2}$ \\ Fang Huang ${ }^{3}$ \\ Shuang Liang' \\ Lan Shen ${ }^{2}$ \\ Yi Feng' \\ Ke-Feng Ruan'
}

'Engineering Research Center of Modern Preparation Technology of TCM of Ministry of Education, Shanghai University of Traditional Chinese Medicine, ${ }^{2}$ College of Chinese Materia Medica, Shanghai University of Traditional Chinese Medicine, ${ }^{3}$ Department of Nephrology, Yueyang Hospital of Integrated Traditional Chinese and Western Medicine, Shanghai University of Traditional Chinese Medicine, Shanghai, People's Republic of China

Correspondence: Yi Feng

Engineering Research Center of Modern Preparation Technology of TCM of

Ministry of Education, Shanghai University of Traditional Chinese Medicine, Shanghai 20I203, People's Republic of China

Tel/Fax +86 2I 5 I 32 249|

Emailyy090503@163.com
Background: Radix ophiopogonis polysaccharide (ROP) has been found to be effective against myocardial ischemia. One of main problems with its use is its short in-vivo half-life, which makes the development of an effective delivery system necessary. To achieve better therapeutic effects and patient compliance by prolonging its retention in plasma and increasing its distribution in targets, ROP was PEGylated (PEG, polyethylene glycol) in this study.

Methods: Through a moderate coupling reaction between hydroxyl-activated ROP and aminoterminated methoxy-PEG (mPEG) (30 or $40 \mathrm{kDa})$, together with a greater than 1 molar ratio of ROP to $\mathrm{mPEG}$ in reaction, long-circulating and potentially bioactive PEGylated ROPs, with PEG grafting number of $\sim 1.0$, were prepared, characterized, and the pharmacokinetics evaluated.

Results: Relative to ROP, whose half-life was approximately 0.7 hours, the two conjugates prepared, following intravenous administration, showed markedly prolonged retention in systemic circulation with half-lives in blood of 78.4 and 88.3 hours, respectively. When given subcutaneously, their in-vivo mean residence times were further markedly prolonged by the slow absorption phase. They were found to be well absorbed after subcutaneous administration, with absolute bioavailability being $75.4 \%$ and $43.9 \%$, respectively.

Conclusion: With apparent molecular masses not exceeding $43 \mathrm{kDa}$, the conjugates prepared have been and will be demonstrated to have prominent advantages for ROP delivery, such as: the good absorption following subcutaneous, intramuscular, or other ways of administration; the effective utilization of the enhanced permeability and retention effect caused by ischemia; and the rapid diffusion within target tissues.

Keywords: radix ophiopogonis polysaccharide, polyethylene glycol, conjugation, pharmacokinetics

\section{Introduction}

Presently, there are many macromolecular drugs, either marketed or developing, having a short plasma half-life following injection administration due to immunogenicity, low stability in vivo, and/or rapid glomerular filtration. Several approaches, including loading the drug in various long-circulating colloidal delivery systems and modifying the drug chemically, have been developed to improve the pharmacokinetic and pharmacodynamic profiles of such drugs. ${ }^{1,2}$ Among these approaches, polymer conjugation, the process of covalent attachment of polymer chain(s) to a drug molecule, has grown fast in the last few years and has already resulted in a number of products available in the marketplace. ${ }^{2,3}$ Many synthetic, semisynthetic, and natural polymers have been investigated as candidates for polymer conjugation, among which, polyethylene glycol (PEG) is the most successful one due to its unique advantages: (1) little antigenicity, immunogenicity and toxicity; (2) high solubility in many solvents; (3) highly hydrated and flexible backbone; and (4) approval by the Food and Drug Administration for human use in injectable 
formulations. PEGylation has been becoming the strategy of choice for optimizing delivery of parenteral agents., ${ }^{4,5}$

Radix ophiopogonis polysaccharide (ROP), a natural graminan-type fructan with weight average molecular weight $\left(M_{\mathrm{w}}\right)$ of $\sim 5 \mathrm{kDa}$, has been found to be very effective against myocardial ischemia. ${ }^{6,7}$ However, due to its unusual properties, ROP is rarely absorbed orally, and is rapidly excreted by the kidneys following intravenous administration. ${ }^{8,9}$ This limits its efficacy and clinical application remarkably. In a previous study, ${ }^{10}$ it was found that the effects of PEGylation on the bioactivity and pharmacokinetics of ROP mainly depend on the grafting degree and the molecular weight of the conjugate, respectively. More specifically, only when the apparent molecular weight of the conjugate approached the glomerular filtration threshold for PEG $(\sim 30 \mathrm{kDa})$ would its plasma elimination reduce abruptly. In general, the conjugation causes the reduction in the bioactivity of ROP; however, well preserved bioactivity is observed when the grafting degree of the conjugate is lower. In another study, it was found that due to the enhanced permeability and retention (EPR) effect caused by ischemia, ${ }^{11,12}$ the distribution of ROP $(\sim 2 \mathrm{~nm})$ is approximately twofold higher in myocardial ischemic rat hearts than in normal ones. ${ }^{13}$ However, the utilization of the EPR effect is significantly limited by the rapid glomerular filtration of ROP, making the increase far from ideal. To achieve better therapeutic effects and patient compliance by prolonging its retention in plasma and increasing its distribution in targets, ROP was PEGylated in this study through the reaction of hydroxyl-activated ROP with amino-terminated methoxy-PEG (mPEG) (30 or $40 \mathrm{kDa}$ ) under a greater than 1 molar ratio of ROP to $\mathrm{mPEG}$. By PEGylating ROP in this way, two conjugates, with $\mathrm{mPEG}$ grafting degree of $\sim 1.0$ and thus potentially well preserved bioactivity, were prepared, purified, and characterized, and the pharmacokinetics evaluated.

\section{Materials and methods Materials and animals}

ROP was prepared as described previously. ${ }^{14}$ Briefly, watersoluble components of the tuberous roots of Ophiopogon japonicus (Cixi, Zhejiang province, China) were extracted with ten volumes of water at $95^{\circ} \mathrm{C}-100^{\circ} \mathrm{C}$, followed by centrifugation. After being concentrated to a suitable level ( $1 \mathrm{~mL}$ of extract was pharmacodynamically equivalent to $1 \mathrm{~g}$ of the roots), the extract was precipitated by the addition of five volumes of $95 \%$ ethanol. The resulting precipitate was redissolved in water and purified by ultrafiltration $\left(M_{\mathrm{w}}\right.$ cutoff value of membrane: 10,000$)$ under pressure $(0.3 \mathrm{MPa})$.
Products with molecular weights estimated to be less than 10,000 were further purified using DEAE Sepharose ${ }^{\circledR}$ Fast Flow and Sephadex ${ }^{\circledR}$ G-25 columns (Pharmacia, Uppsala, Sweden) in tandem, eluted with water to obtain ROP. Linear amino-terminated PEG methyl ethers $\left(\mathrm{mPEG}-\mathrm{NH}_{2}\right)$ with $M_{\mathrm{w}}$ 30 and $40 \mathrm{kDa}$ were purchased from Jenkem Technology Co Ltd (Beijing, China). p-Nitrophenyl chloroformate and 4-N, N-(dimethylamino) pyridine (DMAP) were purchased from Fluka (Buchs, Germany). Fluorescein isothiocyanate (FITC) was purchased from Sigma (St Louis, MO). Extra dry dimethyl sulfoxide (DMSO) was purchased from Acros Organics (Geel, Belgium). Dichloromethane $\left(\mathrm{CH}_{2} \mathrm{Cl}_{2}\right)$ and pyridine from Sinopharm Chemical Reagent Co Ltd (Shanghai, China) were dried over $\mathrm{CaH}_{2}$ and $\mathrm{KOH}$, respectively, and distilled prior to use. All other chemicals were of reagent grade and purchased from commercial sources.

Male Sprague-Dawley rats (approximately 6-7 weeks old) were supplied by Lab Animal Center of the Shanghai University of Traditional Chinese Medicine. They were kept in an environmentally controlled breeding room for 4 days before starting the experiments, and fed with standard laboratory food and water ad libitum. The Animal Ethical Experimentation Committee of the Shanghai University of Traditional Chinese Medicine, according to the requirements of the National Act on the Use of Experimental Animals (People's Republic of China), approved all procedures of the animal experiments.

\section{Preparation and characterization of PEGylated ROPs}

PEGylated ROPs were synthesized through a coupling reaction between hydroxyl-activated ROP and amino-terminated mPEG. ${ }^{10}$

In detail, the hydroxyl groups of ROP were activated with $p$-nitrophenyl chloroformate in the presence of DMAP as a catalyst. ROP ( $1 \mathrm{~g}, 0.21 \mathrm{mmol}), p$-nitrophenyl chloroformate (1 g, $4.97 \mathrm{mmol})$, and DMAP (100 mg) were dissolved in $40 \mathrm{~mL}$ of a mixture of DMSO, $\mathrm{CH}_{2} \mathrm{Cl}_{2}$, and pyridine $(2: 1: 1$ in volume ratio) and kept at $0^{\circ} \mathrm{C}$ for 2 hours. The product was precipitated in $360 \mathrm{~mL}$ of a cold diethyl ether/ethanol $(1: 1, \mathrm{v} / \mathrm{v})$ mixture and filtered. The final product was washed at least nine times with the precipitation reagent and dried in vacuo for 24 hours. The yield was approximately $90 \%$. The $p$-nitrophenyl carbonate content of each activated ROP, which was determined spectrometrically, ${ }^{15}$ was approximately 13 per 100 fructose units.

The activated ROP and $\mathrm{mPEG}-\mathrm{NH}_{2}$ (30 or $40 \mathrm{kDa}$ ) were dissolved in a mixture of DMSO/pyridine $(1: 1, \mathrm{v} / \mathrm{v})$. 
The molar ratio of ROP to $\mathrm{mPEG}-\mathrm{NH}_{2}$ was set at 10:1 in this study so that conjugates with a PEG grafting number approaching 1.0 were prepared. The reaction mixture was stirred for 4 days at room temperature and then added to a cold diethyl ether/ethanol $(3: 1, \mathrm{v} / \mathrm{v})$ mixture with stirring. The white precipitate was collected, washed with an excess of the precipitation reagent, and dried in vacuo. The product was dissolved in a $0.01 \mathrm{M} \mathrm{NaOH}$ aqueous solution to hydrolyze the residual $p$-nitrophenyl groups on the conjugate, followed by dialysis and lyophilization.

Characterization of conjugates was carried out by highperformance gel permeation chromatography (HPGPC) in conjunction with anthrone-sulfuric acid colorimetry. ${ }^{10}$ The high-performance liquid chromatography (HPLC) system consisted of a Waters liquid chromatograph and a Waters 2414 refractive index detector (Waters Corporation, Milford, MA). After characterization, the conjugates were labeled with FITC according to a method previously used. ${ }^{10}$

\section{Assay of FITC-labeled conjugates}

The assay system consisted of an Agilent 1200 series (Agilent Technologies, Santa Clara, CA) HPLC with a fluorescence detector set at $\lambda_{\mathrm{ex}} 495 \mathrm{~nm}$ and $\lambda_{\mathrm{em}} 515 \mathrm{~nm}$. Samples were separated by HPGPC using an $8 \mathrm{~mm} \times 300 \mathrm{~mm}$ Shodex ${ }^{\circledR}$ OHpak SB-803 HQ gel-filtration column (Tokyo, Japan). The eluent was $0.1 \mathrm{M}$ phosphate buffer ( $\mathrm{pH}$ 7.4) delivered at a flow rate of $0.5 \mathrm{~mL} / \mathrm{min}$. The chromatographic procedures were performed at $30^{\circ} \mathrm{C}$.

\section{Pharmacokinetic study}

FITC-labeled PEGylated ROP was administered intravenously to rats via tail vein at a dose of $50 \mathrm{mg} / \mathrm{kg}$. Blood samples (approximately $400 \mu \mathrm{L}$ ) were obtained from the orbital sinus at the specified time points and then centrifuged at $3000 \mathrm{rpm}$ for 10 minutes. The separated plasma was frozen at $-20^{\circ} \mathrm{C}$ until assay.

To a $100 \mu \mathrm{L}$ portion of each plasma sample, $40 \mu \mathrm{L}$ of $1 \mathrm{M}$ perchloric acid was added. The mixture was vortexed and then centrifuged at $10,000 \mathrm{rpm}$ for 1 minute to precipitate denatured proteins. The supernatant was neutralized by the addition of $30 \mu \mathrm{L}$ of $1 \mathrm{M} \mathrm{NaOH}$. After centrifugation at $10,000 \mathrm{rpm}$ for 1 minute again, $10 \mu \mathrm{L}$ of the supernatant was assayed by the method described above.

\section{Data analysis}

Data were expressed as means \pm standard deviations. Statistical analyses were assessed using Student's $t$-test. Statistically significant differences were indicated by $P$-values of $<0.05$. The Drug and Statistics (DAS) 2.0 pharmacokinetic program (Chinese Pharmacology Society, Beijing, China) was used to calculate pharmacokinetic parameters such as area under the curve (AUC), mean residence time (MRT), terminal phase half-life $\left(t_{1 / 2}\right)$, total volume of distribution $\left(\mathrm{V}_{\mathrm{ss}}\right)$, systemic clearance $(\mathrm{CL})$, maximal concentration $\left(\mathrm{C}_{\max }\right)$, time to maximal concentration $\left(\mathrm{T}_{\max }\right)$, and bioavailability by noncompartmental analysis.

\section{Results and discussion Preparation of PEGylated ROPs}

Site-selective PEGylation of drugs is always preferred as it allows easier purification, characterization, and control of products and, most importantly, better preservation of bioactivity of drugs. Several strategies, such as thiol PEGylation, ${ }^{16}$ accessing specific protein amino groups in an appropriate solvent, ${ }^{17}$ blocking some of the reactive groups with a reversible protecting group, ${ }^{18}$ and glycoPEGylation, ${ }^{19}$ had been successfully applied for the site-selective PEGylation of peptides and proteins. However, due to the lack of structure-activity knowledge and reactivity-specific functional group(s), the site-selective PEGylation of polysaccharides is much more difficult than that of peptides and proteins. The strategy, using few high molecular mass PEG chains rather than a higher number of low molecular ones, is therefore especially important for the PEGylation of polysaccharide-based drugs. In addition, with the exception of conjugation sites, no changes in the other sites of polysaccharides are preferred. Several methods had been reported to PEGylate neutral polysaccharides like dextran ${ }^{20-23}$ and inulin. ${ }^{24,25}$ Among these methods, the one used in the study, which utilizes a moderate coupling reaction between the hydroxyl-activated polysaccharide and the amino-terminated mPEG, was believed to be more suitable for PEGylation of polysaccharide-based drugs than those that cause charged conjugates ${ }^{21}$ or require highly alkaline conditions for the coupling, ${ }^{23}$ since it allows the unreacted activated hydroxyls of polysaccharide to return to their original form easily by hydrolysis in a weakly alkaline solution and thus ensures the least influence on the polysaccharide structure and, in turn, on bioactivity. This, coupled with a greater than 1 molar ratio of ROP to $\mathrm{mPEG}$ in reaction, makes sure that the conjugates, with $\mathrm{mPEG}$ grafting degree of $\sim 1.0$ and thus potentially well preserved bioactivity, were prepared. It was found that excessive ROP was easily removed from products by dialysis due to the great disparity in apparent molecular mass between ROP and the conjugates. 
Table I Characterization of mPEG-ROP conjugates

\begin{tabular}{|c|c|c|c|c|c|c|}
\hline Materials and conjugates & $M_{n}(\mathrm{Da})$ & $M_{w}(D a)$ & $M_{p}(\mathrm{Da})$ & Polydispersity index & Grafting degree & Designation \\
\hline ROP & 1738 & 2055 & 1991 & 1.18 & - & - \\
\hline $30 \mathrm{kDa}$ mPEG-NH & 30836 & 33099 & 34522 & 1.06 & - & - \\
\hline $40 \mathrm{kDa}$ mPEG-NH & 34873 & 41380 & 48015 & 1.19 & - & - \\
\hline $\mathrm{mPEG}_{30 \mathrm{k}}-\mathrm{ROP}$ & 32373 & 34864 & 34646 & 1.08 & 0.991 & ${ }_{0.99} \mathrm{P}_{30 \mathrm{k}}-\mathrm{R}$ \\
\hline $\mathrm{mPEG}_{40 \mathrm{k}}-\mathrm{ROP}$ & 35724 & 42721 & 49479 & 1.20 & 0.983 & ${ }_{0.98} \mathrm{P}_{40 \mathrm{k}}-\mathrm{R}$ \\
\hline
\end{tabular}

Abbreviations: $M_{n}$, number average molecular weight; $M_{p}$, peak average molecular weight; $M_{w}$, weight average molecular weight; mPEG, methoxy-polyethylene glycol; ROP, radix ophiopogonis polysaccharide.

\section{Characterization of conjugates and FITC-labeled conjugates}

Characterization of PEGylated ROPs is pretty challenging because both PEG and ROP are neutral and hydrophilic macromolecules as well as lack chromophoric groups. To date, nuclear magnetic resonance (NMR) and gel permeation chromatography (or size-exclusion chromatography) are the most commonly used methods to characterize PEGylated polysaccharides. Since ROP is a fructan and thus lacks an anomeric proton, the ${ }^{1} \mathrm{H}$ NMR method used to determine the grafting degree of PEGylated dextrans ${ }^{20}$ was found to be inapplicable for PEGylated ROPs. It was also found that the confirmation of PEGylation by ${ }^{1} \mathrm{H}$ NMR or Fourier transform infrared spectroscopy was impractical due to the very few carbamate bonds in the conjugates prepared. In this study, they were therefore characterized by HPGPC in conjunction with the carbohydrate-specific anthrone-sulfuric acid colorimetry. PEGylation was affirmed mainly by (1) the slightly left-shifted HPGPC peaks and increased polydispersity indices of the conjugates when compared with the mPEG agents used, and more importantly, (2) the positive chromogenic reaction between the anthrone-sulfuric acid reagent and the eluate corresponding to the HPGPC peak for each conjugate. The calculated apparent molecular masses and PEG-grafting numbers for the conjugates are listed in Table 1. For convenience, in the following description, the conjugates are denoted as ${ }_{0.99} \mathrm{P}_{30 \mathrm{k}}-\mathrm{R}$ and ${ }_{0.98} \mathrm{P}_{40 \mathrm{k}}-\mathrm{R}$, respectively. Due to the lack of specific microassay methods, the conjugates were pre-labeled with FITC to study their pharmacokinetics. In terms of the very low substitution degrees (approximately 0.25 and 0.15 mol FITC per mol ${ }_{0.99} \mathrm{P}_{30 \mathrm{k}}-\mathrm{R}$ and ${ }_{0.98} \mathrm{P}_{40 \mathrm{k}}-\mathrm{R}$, respectively), pharmacokinetic behaviors of the FITC-labeled conjugates were believed to be similar to those of native conjugates.

\section{Validation of the determination method for pharmacokinetic study}

FITC pre-labeling coupled with HPGPC was used in this study to determine the conjugates in rat plasma and urine.
The method was validated for specificity, linearity, precision, accuracy, sensitivity, recovery, and stability. The results showed that the method was specific for the conjugates and no obvious breakages of the conjugates were observed during the study (Figure 1). The typical retention times for FITC-labeled ROP, ${ }_{0.99} \mathrm{P}_{30 \mathrm{k}}-\mathrm{R}$, and ${ }_{0.98} \mathrm{P}_{40 \mathrm{k}}-\mathrm{R}$ were approximately $19.4,14.5$, and 13.9 minutes, respectively. The linearity between the chromatographic peak height and the concentration was evident over the concentration range studied (4-972 $\mu \mathrm{g} / \mathrm{mL}$ and 6-1458 $\mu \mathrm{g} / \mathrm{mL}$ for FITC-labeled ${ }_{0.99} \mathrm{P}_{30 \mathrm{k}}-\mathrm{R}$ and ${ }_{0.98} \mathrm{P}_{40 \mathrm{k}}-\mathrm{R}$, respectively), with correlation coefficients larger than 0.998 . The detection limits for ${ }_{0.99} \mathrm{P}_{30 \mathrm{k}}-\mathrm{R}$ and ${ }_{0.98} \mathrm{P}_{40 \mathrm{k}}-\mathrm{R}$ were both approximately $2 \mu \mathrm{g} / \mathrm{mL}$. The precision and accuracy of the method were examined by adding known amounts of FITC-labeled conjugates to blank rat plasma. The inter- and intraday precisions of analysis were not more than $10 \%$, and assay accuracy ranged from $92 \%$ to $106 \%$ (Table 2). The absolute recoveries of FITC-labeled conjugates were tested at three quality control levels by comparing the calculated concentrations from pretreated plasma samples with those found by direct injection of standard solutions at the same concentration, which were found to be between $58.9 \%$ and $77.3 \%$ (Table 2). Analysis of biosamples for storage and freeze-thaw stability testing consistently afforded values that
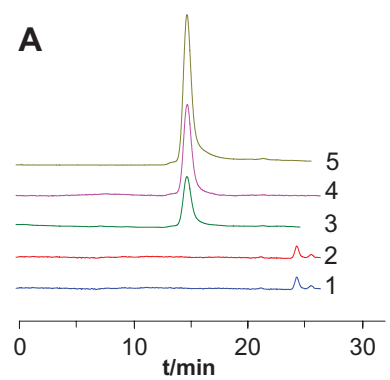

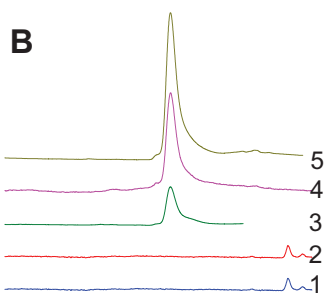

0

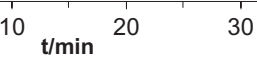

Figure I Representative chromatograms for determination of FITC-labeled (A) ${ }_{0.99} \mathrm{P}_{30 \mathrm{k}}-\mathrm{R}$ and (B) ${ }_{0.98} \mathrm{P}_{40 \mathrm{k}}-\mathrm{R}$ in rat plasma by HPGPC.

Notes: I, blank plasma; 2 , blank urine; 3 , urine samples collected after administration of FITC-labeled conjugates; 4, blank plasma spiked with FITC-labeled conjugates; 5, plasma samples collected after administration of FITC-labeled conjugates.

Abbreviations: FITC, fluorescein isothiocyanate; HPGPC, high-performance gel permeation chromatography; $\mathrm{P}$, methoxy-polyethylene glycol; $\mathrm{R}$, radix ophiopogonis polysaccharide. 
Table 2 Recovery, precision, and accuracy for the assay of FITC-labeled mPEG-ROP conjugates in rat plasma by HPGPC ( $n=5$ )

\begin{tabular}{|c|c|c|c|c|c|}
\hline \multirow[t]{2}{*}{ Conjugate } & \multirow[t]{2}{*}{ Concentration $(\mu \mathrm{g} / \mathrm{mL})$} & \multirow[t]{2}{*}{ Recovery (\%) } & \multirow[t]{2}{*}{ Accuracy (\%) } & \multicolumn{2}{|c|}{ Precision RSD (\%) } \\
\hline & & & & Intraday & Interday \\
\hline \multirow{3}{*}{${ }_{0.99} P_{30 k}-R$} & 10 & $58.9 \pm 4.7$ & $102 \pm 8.2$ & 8.04 & 8.96 \\
\hline & 70 & $77.3 \pm 4.4$ & $103 \pm 5.9$ & 5.75 & 8.61 \\
\hline & 700 & $61.7 \pm 3.1$ & $94.8 \pm 4.8$ & 5.05 & 7.27 \\
\hline \multirow{3}{*}{${ }_{0.98} P_{40 k}-R$} & 10 & $69.5 \pm 6.9$ & $106 \pm 10.6$ & 10.0 & 9.26 \\
\hline & 100 & $70.0 \pm 5.7$ & $95.5 \pm 7.8$ & 8.14 & 7.45 \\
\hline & 1000 & $62.7 \pm 1.3$ & $92.4 \pm 2.0$ & 2.14 & 6.93 \\
\hline
\end{tabular}

Abbreviations: FITC, fluorescein isothiocyanate; HPGPC, high-performance gel permeation chromatography; mPEG, methoxy-polyethylene glycol; P, mPEG; R, ROP; ROP, radix ophiopogonis polysaccharide; RSD, relative standard deviation.

were nearly identical to those of freshly prepared biosamples (the relative error was within $\pm 15 \%$ ). All the results demonstrated that the method was accurate, specific, and stable.

\section{Pharmacokinetics of PEGylated ROPs}

In a previous study, ${ }^{26}$ the pharmacokinetics of a longcirculating and bioactive PEGylated ROP with an average $1.03 \mathrm{mEPG}(20 \mathrm{kDa})$ residues per single ROP (denoted as ${ }_{1.03} \mathrm{P}_{20 \mathrm{k}}-\mathrm{R}$ ) was investigated following intravenous or subcutaneous administration at three dose levels $(9,20$, and $50 \mathrm{mg} / \mathrm{kg}$ ) in rats. An evident linear correlation was observed between administration doses and areas under the plasma ${ }_{1.03} \mathrm{P}_{20 \mathrm{k}}-\mathrm{R}$ level versus time profile, regardless of the administration route. The tissue distribution of ${ }_{1.04} \mathrm{P}_{20 \mathrm{k}}-\mathrm{R}$ in mice with normal and ischemic myocardium was also studied. ${ }^{27}$ The results show that the AUC of ${ }_{1.04} \mathrm{P}_{20 \mathrm{k}}-\mathrm{R}$ in ischemic hearts was approximately 1.6-fold greater than in normal hearts, indicating that the conjugate still could effectively use the EPR effect caused by ischemia to passively target ischemic myocardia.

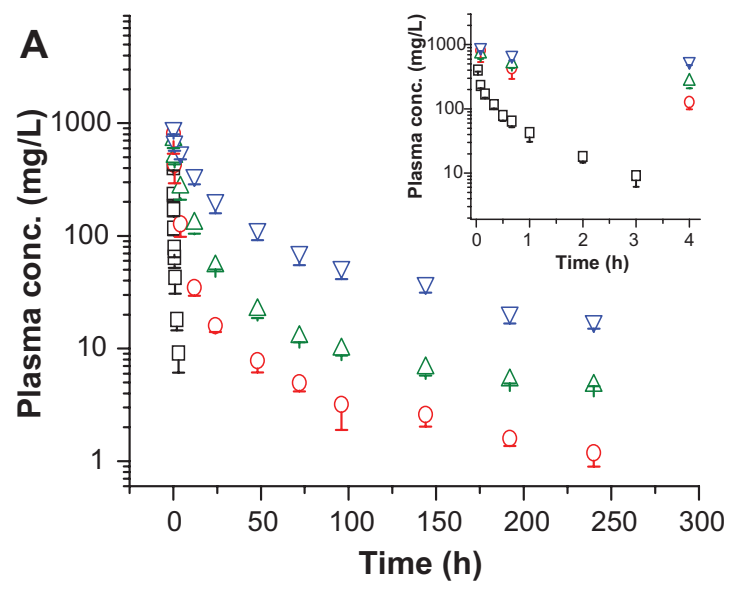

In this study, pharmacokinetic properties of two more long-circulating PEGylated ROPs, namely ${ }_{0.99} \mathrm{P}_{30 \mathrm{k}}-\mathrm{R}$ and ${ }_{0.98} \mathrm{P}_{40 \mathrm{k}}-\mathrm{R}$, were evaluated in rats following intravenous or subcutaneous administration at a dose of $50 \mathrm{mg} / \mathrm{kg}$. For comparison, blood plasma level-time profiles for ROP, ${ }_{1.03} \mathrm{P}_{20 \mathrm{k}}-\mathrm{R},{ }_{0.99} \mathrm{P}_{30 \mathrm{k}}-\mathrm{R}$, and ${ }_{0.98} \mathrm{P}_{40 \mathrm{k}}-\mathrm{R}$ are together shown in Figure 2, and main pharmacokinetic parameters are listed in Tables 3 and 4. Relative to ROP, whose half-life was approximately 0.7 hours, ${ }_{1.03} \mathrm{P}_{20 \mathrm{k}}-\mathrm{R},{ }_{0.99} \mathrm{P}_{30 \mathrm{k}}-\mathrm{R}$, and ${ }_{0.98} \mathrm{P}_{40 \mathrm{k}}-\mathrm{R}$, following intravenous administration, showed markedly prolonged retention in systemic circulation, with half-lives in blood of 35.6, 78.4, and 88.3 hours, respectively. Just as for polysaccharides, PEGs, and PEGylated proteins, all of the three PEGylated ROPs displayed multicompartmental pharmacokinetics (Figure 2A). When the conjugates were given subcutaneously, their MRTs were further remarkably prolonged by the slow absorption phase. The absorption halflives of ${ }_{1.03} \mathrm{P}_{20 \mathrm{k}}-\mathrm{R},{ }_{0.99} \mathrm{P}_{30 \mathrm{k}}-\mathrm{R}$, and ${ }_{0.98} \mathrm{P}_{40 \mathrm{k}}-\mathrm{R}$ were $24.9,24.1$, and 33.2 hours, respectively, approximately $137-188$ times that of ROP. All the conjugates were found to be well absorbed after

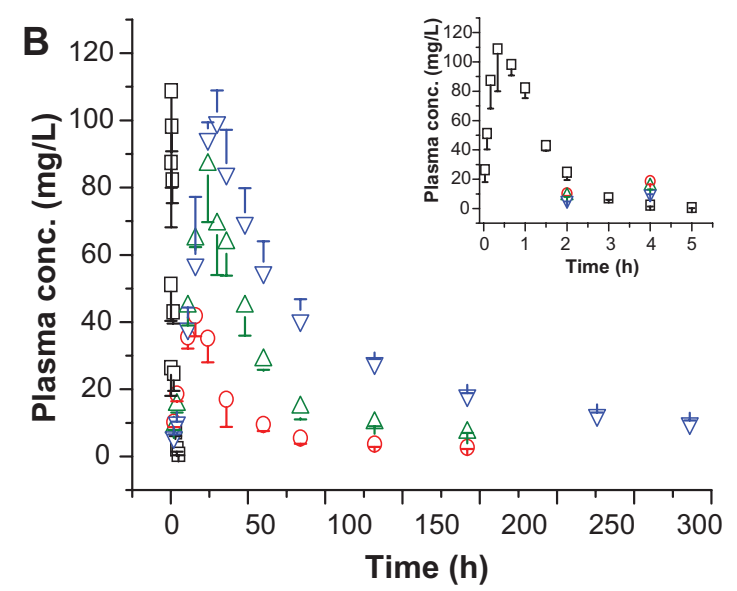

Figure 2 Plasma FITC-labeled ROP (open squares), ${ }_{1.03} \mathrm{P}_{20 \mathrm{k}}-\mathrm{R}$ (open circles), ${ }_{0.99} \mathrm{P}_{30 \mathrm{k}}-\mathrm{R}$ (open up-triangles), or ${ }_{0.98} \mathrm{P}_{40 \mathrm{k}}-\mathrm{R}$ (open down-triangles) level versus time profiles following (A) intravenous or (B) subcutaneous administration at $50 \mathrm{mg} / \mathrm{kg}$ to rats.

Note: Each data point represents the mean \pm standard deviation for triplicate experiments.

Abbreviations: conc, concentration; FITC, fluorescein isothiocyanate; P, methoxy-polyethylene glycol; R, ROP; ROP, radix ophiopogonis polysaccharide. 
Table 3 Rat pharmacokinetic parameters following intravenous administration of $50 \mathrm{mg} / \mathrm{kg} \mathrm{mPEG}-\mathrm{ROP}$ conjugates (means \pm SD, $n=3$ )

\begin{tabular}{|c|c|c|c|c|}
\hline Parameter $^{a}$ & ROP $^{10}$ & ${ }_{1.03} \mathbf{P}_{20 \mathrm{k}}-\mathbf{R}^{26}$ & ${ }_{0.99} \mathbf{P}_{30 \mathrm{k}}-\mathbf{R}$ & ${ }_{0.98} \mathbf{P}_{40 \mathrm{k}}-\mathbf{R}$ \\
\hline$A \cup C_{0-\infty}(g \cdot h / L)$ & $0.170 \pm 0.024$ & $3.05 \pm 0.45$ & $7.30 \pm 0.94$ & $23.7 \pm 4.5^{b}$ \\
\hline $\mathrm{MRT}_{0-\infty}$ (hours) & $0.826 \pm 0.031$ & $22.4 \pm 8.0$ & $54.4 \pm 12.7$ & $83.2 \pm 2.6^{c}$ \\
\hline$t_{1 / 2}$ (hours) $^{\mathrm{d}}$ & $0.724 \pm 0.004$ & $35.6 \pm 9.0$ & $78.4 \pm 12.2$ & $88.3 \pm 3.0^{\mathrm{e}}$ \\
\hline $\mathrm{V}_{\mathrm{ss}}(\mathrm{mL} / \mathrm{kg})$ & $314 \pm 46$ & $853 \pm 217$ & $778 \pm 109$ & $276 \pm 60$ \\
\hline CL (L/h per kg) & $0.300 \pm 0.044$ & $0.017 \pm 0.003$ & $0.007 \pm 0.001$ & $0.002 \pm 0.000$ \\
\hline
\end{tabular}

Notes: a Calculated by noncompartmental moment analysis assuming first-order elimination; ${ }^{b P}<0.01$, compared with ${ }_{0.99} P_{30 k}-R ;{ }^{c} P<0.05$, compared with ${ }_{0.99} P_{30 k}-R$; ${ }^{d}$ calculated from the elimination rate constant $\left(\lambda_{z}\right)$ using the formula $t_{1 / 2}=0.693 / \lambda_{z} ; \quad P>0.05$, compared with ${ }_{0.99} P_{30 k}-R$.

Abbreviations: AUC, area under the curve; CL, systemic clearance; mPEG, methoxy-polyethylene glycol; MRT, mean residence time; P, mPEG; R, ROP; ROP, radix ophiopogonis polysaccharide; SD, standard deviation; $t_{1 / 2}$, half-life; $\mathrm{V}_{\mathrm{s}}$, total volume of distribution.

subcutaneous administration, with absolute bioavailability being $68.9 \%, 75.4 \%$, and $43.9 \%$, respectively. This indicates that it is promising to give them in such a more convenient and safer way so as to achieve better therapeutic effects and patient compliance. After subcutaneous administration, macromolecules may be transported to systemic circulation directly via blood capillaries or indirectly via lymphatics, both of which contribute to the absorption of materials from the subcutaneous tissue. Studies have shown that greater than $50 \%$ of a subcutaneous dose may be taken up by the peripheral lymphatics for macromolecules whose molecular mass exceeds approximately $20 \mathrm{kDa} \cdot{ }^{28-30}$ Molecular weight, or size, is also thought to be the primary determinant for the absorption route of macromolecules after subcutaneous administration. ${ }^{29,31}$ In terms of their molecular masses, the two conjugates prepared in this study were, therefore, believed to be mainly absorbed into blood indirectly via lymphatics. Moreover, according to HPGPC chromatograms obtained in the pharmacokinetic study, it was believed that the majority, if not all, of the conjugates transported into lymphatics could survive from the lymphatic system and reach blood undegraded. With larger hydrodynamic volumes and longer plasma residence times, ${ }_{0.99} \mathrm{P}_{30 \mathrm{k}}-\mathrm{R}$ and ${ }_{0.98} \mathrm{P}_{40 \mathrm{k}}-\mathrm{R}$ are also expected to be able to passively target ischemic myocardia more effectively by the EPR effect than ${ }_{1.04} \mathrm{P}_{20 \mathrm{k}} \mathrm{R}$.

In another study, ${ }^{10}$ several other PEGylated ROPs $\left({ }_{0.8} \mathrm{P}_{2 \mathrm{k}}-\mathrm{R}\right.$, ${ }_{4.0} \mathrm{P}_{2 \mathrm{k}}-\mathrm{R},{ }_{1.1} \mathrm{P}_{5 \mathrm{k}}-\mathrm{R}$, and ${ }_{5.4} \mathrm{P}_{5 \mathrm{k}}-\mathrm{R}$, with apparent molecular masses of $3.8,10.4,8.3$, and $31.2 \mathrm{kDa}$, respectively) had been prepared and evaluated in pharmacokinetics. The results, together with those obtained here, clearly indicate a sigmoidal-shaped relation between the apparent molecular masses and the halflives of PEGylated ROPs (Figure 3). The apparent molecular mass corresponding to the mean point of the sigmoid is $25.4 \mathrm{kDa}$, which is a little lower than the reported glomerular filtration threshold for PEG $(\sim 30 \mathrm{kDa}){ }^{32,33}$ ROP is a highly branched fructan, having a backbone composed of Fruf $(2 \rightarrow 1)$ and a branch of Fruf $(2 \rightarrow 6) \operatorname{Fruf}(2 \rightarrow$ per average 2.8 of main chain residues. ${ }^{14}$ By atom force microscope, it was found that ROP appeared to be spherical at a concentration of $0.1 \mathrm{mg} / \mathrm{mL}{ }^{7}$ Therefore, $\mathrm{mPEG}$-ROP conjugates were believed to be more spherical and have lower flexibility and deformability in blood than linear mPEG agents alone. This allowed for their more difficult glomerular filtration, especially when their sizes were around the sieving threshold of the glomerular capillary wall $(\sim 10 \mathrm{~nm})^{34}$ and was believed to be the reason for the just-mentioned disparity. This finding also coincides

Table 4 Rat pharmacokinetic parameters following subcutaneous administration of $50 \mathrm{mg} / \mathrm{kg} \mathrm{mPEG}-\mathrm{ROP}$ conjugates (means $\pm \mathrm{SD}, n=3$ )

\begin{tabular}{lcccc}
\hline Parameter $^{\mathrm{a}}$ & ROP & ${ }_{.03} \mathbf{P}_{20 \mathrm{k}}-\mathbf{R}^{26}$ & ${ }_{0.99} \mathbf{P}_{30 \mathrm{k}}-\mathbf{R}$ & ${ }_{0.98} \mathbf{P}_{40 \mathrm{k}}-\mathbf{R}$ \\
\hline $\mathrm{AUC}_{0-\infty}(\mathrm{g} \cdot \mathrm{h} / \mathrm{L})$ & $0.160 \pm 0.010$ & $2.10 \pm 0.46$ & $5.50 \pm 0.74$ & $10.4 \pm 0.8^{\mathrm{b}}$ \\
$\mathrm{MRT}_{0-\infty}($ hours $)$ & $1.08 \pm 0.04$ & $58.4 \pm 8.7$ & $89.2 \pm 1.3$ & $131 \pm 6^{\mathrm{b}}$ \\
$t_{1 / 2}(\text { hours})^{\mathrm{c}}$ & $0.577 \pm 0.082$ & $35.1 \pm 15.7$ & $66.8 \pm 9.0$ & $89.2 \pm 4.4^{\mathrm{d}}$ \\
$\mathrm{k}_{\mathrm{a}}\left(\times 10^{-2}\right)^{\mathrm{e}}$ & 394 & 2.78 & 2.87 & 2.09 \\
$\mathrm{C}_{\max }(\mathrm{mg} / \mathrm{L})$ & $118 \pm 13$ & $43.7 \pm 4.5$ & $86.8 \pm 17.1$ & $99.4 \pm 9.4^{\mathrm{f}}$ \\
$\mathrm{T}_{\max }($ hours & $0.444 \pm 0.192$ & $18.7 \pm 4.6$ & $24.0 \pm 0.0$ & $30.0 \pm 0.0$ \\
$\mathrm{~F}(\%)$ & 94.1 & 68.9 & 75.4 & 43.9 \\
$\mathrm{CL} / \mathrm{F}(\mathrm{L} / \mathrm{h}$ per $\mathrm{kg})$ & $0.328 \pm 0.020$ & $0.025 \pm 0.005$ & $0.009 \pm 0.001$ & $0.005 \pm 0.001$ \\
\hline
\end{tabular}

Notes: ${ }^{\mathrm{C} C}$ alculated by noncompartmental moment analysis assuming first-order elimination; ${ }^{\mathrm{b}} \mathrm{P}<0.0 \mathrm{I}$, compared with ${ }_{0.99} \mathrm{P}_{30 \mathrm{k}}-\mathrm{R}$; ${ }^{\mathrm{c}}{ }^{\mathrm{c}} \mathrm{clculated}$ from the elimination rate constant $\left(\lambda_{\mathrm{z}}\right)$ using the formula $t_{1 / 2}=0.693 / \lambda_{\mathrm{z}} ;{ }^{\mathrm{d}} \mathrm{P}<0.05$, compared with ${ }_{0.99} \mathrm{P}_{30 \mathrm{k}}-\mathrm{R}$; ${ }^{\mathrm{e} e s t i m a t e d}$ as the reciprocal of MAT (MAT $\left.=\mathrm{MRT}_{\text {sc }}-\mathrm{MRT}_{\mathrm{iv}}\right)$; ${ }^{\mathrm{f}} \mathrm{P}>0.05$, compared with $0.99 \mathrm{P}_{30 \mathrm{k}}-\mathrm{R}$. Abbreviations: AUC, area under the curve; CL, systemic clearance; $\mathrm{C}_{\max }$, maximal concentration; $\mathrm{F}$, absolute bioavailability; $k_{\mathrm{a}}$, absorption rate constant; mPEG, methoxy-polyethylene glycol; MRT, mean residence time; $M R T_{\text {iv }}, M R T$ intravenous; MRT $_{\text {sc }}, M R T$ subcutaneous; $P$, mPEG; R, ROP; ROP, radix ophiopogonis polysaccharide; $\mathrm{SD}$, standard deviation; $t_{1 / 2}$, half-life; $\mathrm{T}_{\max }$, time to maximal concentration. 


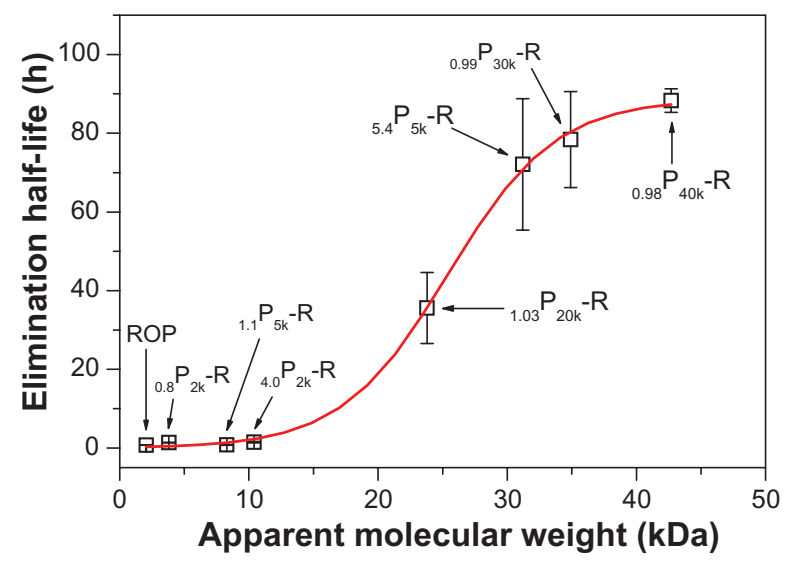

Figure 3 Relationship between the apparent weight average molecular weights and the elimination half-lives of PEGylated ROPs.

Note: Each data point represents the mean \pm standard deviation for triplicate experiments.

Abbreviations: PEG, polyethylene glycol; ROP, radix ophiopogonis polysaccharide.

with the conclusion obtained by Arendshorst and Navar, who demonstrated that glomerular filtration of macromolecules was related not only to their size and charge but also to their shape and rigidity. ${ }^{35}$ In addition, the sigmoid also indicated that $\mathrm{mPEG}-\mathrm{NH}_{2}$ with molecular mass above $40 \mathrm{kDa}$ might not be suitable for PEGylation of ROP due to both the limited further increase in elimination half-life and the increased possibility of accumulation of the agents in the body.

\section{Conclusion}

Through a moderate coupling reaction between hydroxylactivated ROP and amino-terminated $\mathrm{mPEG}$ with proper molecular weight $(\geq 20 \mathrm{kDa})$ together with a greater than 1 molar ratio of ROP to $\mathrm{mPEG}$ in reaction, long-circulating PEGylated ROPs, with PEG-grafting degree of $\sim 1.0$ and thus potentially well preserved bioactivity, can be prepared. Characterization of PEGylated ROPs can be carried out by HPGPC in conjunction with the carbohydrate-specific anthrone-sulfuric acid colorimetry. With apparent molecular masses not exceeding $43 \mathrm{kDa}$, the conjugates prepared in this study have been and will be demonstrated to have the variety of prominent advantages for ROP delivery, such as the long residence time in blood, the good absorption following subcutaneous, intramuscular, or other ways of administration, the effective utilization of the EPR effect caused by ischemia, and the rapid diffusion within target tissues.

\section{Acknowledgments}

This work was supported by the National Natural Science Foundation of China (No 81073065), the Shanghai RisingStar Program (No 07QA14050), the Shanghai Science and
Technology Committee Item (No 09DZ1973000), the Key Discipline Project of Shanghai Education Committee (No J50302), and the Xinglin Scholar Program of Shanghai University of Traditional Chinese Medicine.

\section{Disclosure}

The authors report no conflicts of interest in this work.

\section{References}

1. Davis ME, Chen ZG, Shin DM. Nanoparticle therapeutics: an emerging treatment modality for cancer. Nat Rev Drug Discov. 2008;7:771-782.

2. Duncan R. The dawning era of polymer therapeutics. Nat Rev Drug Discov. 2003;2:347-360.

3. Pasut G, Veronese FM. Polymer-drug conjugation, recent achievements and general strategies. Prog Polym Sci. 2007;32:933-961.

4. Kang JS, DeLuca PP, Lee KC. Emerging PEGylated drugs. Expert Opin Emerg Drugs. 2009;14:363-380.

5. Harris JM, Chess RB. Effect of PEGylation on pharmaceuticals. Nat Rev Drug Discov. 2003;2:214-221.

6. Wang S, Zhang Z, Lin X, Xu DS, Feng Y, Ding K. A polysaccharide, MDG-1, induces $\mathrm{S}_{1} \mathrm{P}_{1}$ and $\mathrm{bFGF}$ expression and augments survival and angiogenesis in the ischemic heart. Glycobiology. 2010;20:473-484.

7. Zheng Q, Feng Y, Xu DS, Lin X, Chen YZ. Influence of sulfation on anti-myocardial ischemic activity of Ophiopogon japonicus polysaccharide. J Asian Nat Prod Res. 2009;11:306-321.

8. Lin X, Xu DS, Feng Y, Shen L. Determination of Ophiopogon japonicus polysaccharide in plasma by HPLC with modified postcolumn fluorescence derivatization. Anal Biochem. 2005;342:179-185.

9. Lin X, Xu DS, Feng Y, Li SM, Lu ZL, Shen L. Release-controlling absorption enhancement of enterally administered Ophiopogon japonicus polysaccharide by sodium caprate in rats. J Pharm Sci.2006; 95:2534-2542.

10. Lin X, Wang S, Jiang Y, et al. Poly(ethylene glycol)-radix ophiopogonis polysaccharide conjugates: preparation, characterization, pharmacokinetics and in vitro bioactivity. Eur J Pharm Biopharm. 2010;76:230-237.

11. Rodriguez M, Cai WJ, Kostin S, Lucchesi BR, Schaper J. Ischemia depletes dystrophin and inhibits protein synthesis in the canine heart: mechanism of myocardial ischemic injury. J Mol Cell Cardiol. 2005; 38:723-733.

12. Lukyanov AN, Hartner WC, Torchilin VP. Increased accumulation of PEG-PE micelles in the area of experimental myocardial infarction in rabbits. J Control Release. 2004;94:187-193.

13. Lin X, Wang Z, Sun G, Shen L, Xu D, Feng Y. A sensitive and specific HPGPC-FD method for the study of pharmacokinetics and tissue distribution of radix ophiopogonis polysaccharide in rats. Biomed Chromatogr. 2010;24:820-825.

14. Xu DS, Feng Y, Lin X, Deng HL, Fang JN, Dong Q. Isolation, purification and structural analysis of a polysaccharide MDG-1 from Ophiopogon Japonicus. Acta Pharmaceut Sin. 2005;40:636-639.

15. Chiu HC, Konak C, Kopeckova P, Kopecek J. Enzymatic degradation of poly(ethylene glycol)-modified dextrans. J Bioactive Compat Polym. 1994;9:388-410.

16. Manjula BN, Tsai A, Upadhya R, et al. Site-specific PEGylation of hemoglobin at Cys-93(beta): correlation between the colligative properties of the PEGylated protein and the length of the conjugated PEG chain. Bioconjug Chem. 2003;14:464-472.

17. Piquet G, Gatti M, Barbero L, Traversa S, Caccia P, Esposito P. Set-up of large laboratory-scale chromatographic separations of poly(ethylene glycol) derivatives of the growth hormone-releasing factor 1-29 analogue. J Chromatogr A. 2002;944:141-148.

18. Hinds KD, Kim SW. Effects of PEG conjugation on insulin properties. Adv Drug Deliv Rev. 2002;54:505-530. 
19. DeFrees S, Wang ZG, Xing R, et al. GlycoPEGylation of recombinant therapeutic proteins produced in Escherichia coli. Glycobiology. 2006; $16: 833-843$.

20. Huh KM, Ooya T, Lee WK, et al. Supramolecular-structured hydrogels showing a reversible phase transition by inclusion complexation between poly(ethylene glycol) grafted dextran and $\alpha$-cyclodextrin. Macromolecules. 2001;34:8657-8662.

21. Lukyanov AN, Sawant RM, Hartner WC, Torchilin VP. PEGylated dextran as long-circulating pharmaceutical carrier. J Biomater Sci Polymer Edn. 2004;15:621-630.

22. Hoste K, Bruneel D, De Marre A, De Schrijver F, Schacht E. Synthesis and characterization of poly(oxyethylene) modified dextrans. Macromol Rapid Commun. 1994;15:697-704.

23. Duval JM, Delestre C, Carre M-C, Hubert P, Dellacherie E. Synthesis and characterization of some covalent dextran-polyoxyethyleneglycol derivatives. Carbohyd Polym. 1991;15:233-242.

24. Rogge TM, Stevens CV, Vandamme A, et al. Application of ethoxylated inulin in water-blown polyurethane foams. Biomacromolecules. 2005;6:1992-1997.

25. Sun G, Lin X, Wang Z, Feng Y, Xu D, Shen L. PEGylated inulin as long-circulating pharmaceutical carrier. J Biomater Sci Polym Ed. 2011;22:429-441

26. Wang ZJ, Lin X, Shen L, Feng Y, Xu DS, Ruan KF. Pharmacokinetics of a long-circulating PEGylated radix ophiopogonis polysaccharide. Acta Pharmaceut Sin. 2011;46(10):1257-1261.

27. Lin X, Wang ZJ, Wang S, et al. Comparison of tissue distribution of a PEGylated radix ophiopogonis polysaccharide in mice with normal and ischemic myocardium. Eur J Pharm Biopharm. 2011;79(3):621-626.
28. Charman SA, Segrave AM, Edwards GA, Porter CJH. Systemic availability and lymphatic transport of human growth hormone administered by subcutaneous injection. J Pharm Sci. 2000;89:168-177.

29. Supersaxo A, Hein WR, Steffen H. Effect of molecular weight on the lymphatic absorption of water-soluble compounds following subcutaneous administration. Pharm Res. 1990;7:167-169.

30. Supersaxo A, Hein W, Gallati H, Steffen H. Recombinant human interferon alpha-2a: delivery to lymphoid tissue by selected modes of application. Pharm Res. 1988;5:472-476.

31. Porter CJ, Charman SA. Lymphatic transport of proteins after subcutaneous administration. J Pharm Sci. 2000;89:297-310.

32. Yamaoka T, Tabata Y, Ikada Y. Distribution and tissue uptake of poly(ethylene glycol) with different molecular weights after intravenous administration to mice. J Pharm Sci. 1994;83:601-606.

33. Greenwald RB, Gilbert CW, Pendri A, Conover CD, Xia J, Martinez A. Drug delivery systems: water soluble taxol 2'-poly(ethylene glycol) ester prodrugs-design and in vivo effectiveness. J Med Chem. 1996; 39:424-431.

34. Venturoli D, Rippe B. Ficoll and dextran vs globular proteins as probes for testing glomerular permselectivity: effects of molecular size, shape, charge, and deformability. Am J Physiol. 2005;288:605-613.

35. Arendshorst WJ, Navar LG. Renal circulation and glomerular hemodynamics. In: Schrier RW, Gottshalk CW, editors. Diseases of the Kidney. Boston, MA: Little, Brown; 1988:65.
International Journal of Nanomedicine

\section{Publish your work in this journal}

The International Journal of Nanomedicine is an international, peerreviewed journal focusing on the application of nanotechnology in diagnostics, therapeutics, and drug delivery systems throughout the biomedical field. This journal is indexed on PubMed Central, MedLine, CAS, SciSearch $\AA$, Current Contents ${ }^{\circledR} /$ Clinical Medicine,

\section{Dovepress}

Journal Citation Reports/Science Edition, EMBase, Scopus and the Elsevier Bibliographic databases. The manuscript management system is completely online and includes a very quick and fair peer-review system, which is all easy to use. Visit http://www.dovepress.com/ testimonials.php to read real quotes from published authors. 